\title{
Dørene lukkes for klimamålene
}

\section{Kristoffer Rypdal}

Institutt for matematikk og statistikk, UiT Norges arktiske universitet, 9037 Troms $\varnothing$

Forfatteren er professor i fysikk og anvendt matematikk ved UiT Norges arktiske universitet, der han har hatt sitt virke i førti år. Forskningen har spent over et bredt felt av temaer i teoretisk og eksperimentell fysikk og anvendt matematikk, mens hovedinteressen i dag er forskning på forholdet mellom menneskeskapte og naturlige klimaendringer. Han leder for tiden et forskningsprosjekt om forsinkelser $i$ klimasystemets respons. Prosjektet er finansiert av KLIMAFORSK-programmet $i$ Norges Forskningsråd.

FNs klimapanel har utarbeidet en rekke prognoser for økningen i global middeltemperatur basert på ulike scenarier for utviklingen av utslipp av drivhusgasser og partikler fra menneskelig aktivitet. Disse prognosene er i hovedsak basert på en lang rekke svært komplekse modeller. De mest komplekse, såkalte jordsystemmodeller, omfatter sirkulasjonen i atmosfære og hav, men også isdynamikk, og kjemiske og biologiske prosesser som innebefatter det svært intrikate kretsløpet for karbon. Basert på disse modellene har klimapanelet anslått at vi bare har få tiår på oss til å redusere utslippene til null hvis vi skal ha mulighet til å nå det såkalte togradersmålet. I denne artikkelen brukes en svært forenklet matematisk modell til å illustrere disse resultatene og gi et inntrykk av usikkerhetene i klimaprognosene.

Etter at klimapanelet i 2013 ga ut sin femte rapport publiserte en av hovedforfatterne, Thomas Stocker, en artikkel i tidsskriftet Science med tittel The Closing Doors of Climate Targets (Stocker, 2013). Her brukte han data fra et stort antall jordsystemmodeller til å vise at tiden er i ferd med å løpe fra oss når det gjelder å begrense global oppvarming til to grader, og at muligheten til å holde oss under 4-5 grader er svært små hvis verdens utslipp ikke starter på en sterkt nedadgående kurs innen få tiår.

\section{Menneskehetens karbonkvote}

Alle realistiske scenarier for $\mathrm{CO}_{2}$-utslipp fra menneskelige aktiviteter må gå ut fra at utslippene tar slutt en gang i framtida. Om ikke annet fordi kloden vil gå tom for fossilt brensel. Utviklingen over tid av den globale middeltemperaturen vil avhenge av takten i utslippene, men det ligger i kortene at temperaturen en gang i framtida vil nå et maksimum og deretter avta langsomt. Stockers artikkel baserer seg på en spesiell observasjon fra simuleringer med forskjellige utslippsscenarier i mange forskjellige jordsystemmodeller. Jevnt over gir modellene det resultat at den maksimale temperaturen bare avhenger av den akkumulerte mengden karbon som blir sluppet ut før de stanser for godt, og ikke av detaljer i tidsforløpet av utslippene. Dette gir grobunn for å hevde at 
menneskeheten har en gitt pott med karbon å slippe ut hvis vi skal holde temperaturøkningen under to grader Celcius målt i forhold til førindustriell tid.

Et problem her er imidlertid at selv om den maksimale temperaturen er proporsjonal med det akkumulerte karbonutslippet, så er det likevel et stort sprik mellom modellene. Dette reflekterer nok først og fremst at vi fortsatt har svært mangelfull kunnskap om naturens karbonkretsløp, og dermed er det usikkert hvor stor menneskehetens karbonkvote egentlig er. Klimapanelet har estimert at den mest sannsynlige størrelsen av denne kvoten er 800 milliarder tonn karbon (GtC). I 2015 var det allerede brukt 550 GtC, så i følge dette estimatet er det vi har igjen å bruke innenfor togradersmålet $250 \mathrm{GtC}$. Dagens utslipp er på om lag $10 \mathrm{GtC}$ per år, som innebærer at selv om vi ikke øker utslippene, så har vi mindre enn 25 år på oss for å gjøre verden karbonnøytral. Usikkerheten i estimatene tilsier at vi må ta disse tallene med en klype salt, men problemet er at vi ikke vet om de er for høye eller for lave.

\section{Jordsystemmodeller}

Enkelte forskere utenfor hovedstrømmen i klimaforskningen innvender at nettopp kompleksiteten av modellene kan gjøre dem upålitelige. Disse forskerne påpeker også at forskjellige modeller inneholder mange felles moduler, og dermed ikke er helt uavhengige. Dette betyr at det kan være systematiske feil som går igjen i mange modeller, og dermed at man ikke nødvendigvis kommer noe nærmere sannheten ved å se på gjennomsnittet av resultater beregnet fra flere modeller. Endelig inneholder modellene mange fysiske parametere som ikke er beregnet fra grunnleggende naturlover og som må bestemmes empirisk fra observasjoner. Modellene er altså i noen grad tilpasset til å gi det riktige svaret for klimautviklingen fram til i dag.

I statistikken kalles dette overtilpasning. Hvis man har en modell med for mange ukjente parametere, og man estimerer verdien av disse parameterne slik at modellen gir best mulig beskrivelse av observerte data, så risikerer man å produsere en modell som gir en feil beskrivelse av naturen, men som er "massert" til å gi en god beskrivelse av eksisterende observasjoner. Disse forskerne mener derfor at det er en stor sjanse for at modellene ikke vil være gode til å levere prognoser for framtidas klima. Jeg tror disse innvendingene er overdrevne, men de kan ikke uten videre avfeies som tøv. De understreker behovet for å supplere med mye enklere og oversiktlige modeller.

\section{Enkle modeller}

Disse vil inneholde færre ukjente parametere, og dermed er risikoen for overtilpasning mindre. De enkle modellene kan vise oss hvilke faktorer som har størst betydning for klimaprognosene, og hvilke som bidrar til størst usikkerhet. I denne artikkelen beskrives en slik modell (K. Rypdal, 2015), som består av tre komponenter. Én komponent beskriver hvordan atmosfærens $\mathrm{CO}_{2}$ konsentrasjon utvikler seg i forskjellige scenarier for menneskelige utslipp. Den andre beskriver hvordan forholdet mellom innstrålt og utstrålt energi (klimapådrivet) endres med endret $\mathrm{CO}_{2}$-konsentrasjon. Og den tredje produserer en prognose for jordas overflatetemperatur når utviklingen av klimapådrivet er 
kjent. Figur 1 viser et flytdiagram for modellen, som består av tre koblete integrallikninger der $\mathrm{CO}_{2}$-utslippene inngår som et kildeledd.

\section{$\mathrm{CO}_{2}$-responsen}

I dag vet man at litt mindre enn halvparten av den $\mathrm{CO}_{2}$-mengden som slippes ut fra menneskelig aktivitet blir værende i atmosfæren. Den andre halvparten blir i hovedsak tatt opp av havet og av vegetasjonen på land. Karbonsyklusen er imidlertid svært komplisert. Hvis det bare var slik at en viss andel av $\mathrm{CO}_{2}-$ overskuddet siden førindustriell tid blir absorbert hvert år, så ville få en halveringstid for karbon i atmosfæren på i overkant av 30 år. Dermed ville naturen raskt bringe $\mathrm{CO}_{2}$-nivåene tilbake til normalen når vi endelig får kontroll på utslippene. Jeg har tatt med dette som en alternativ modell i min studie, selv om jeg er helt sikker på at den er feil, fordi både de øvre lagene i havet og vegetasjonen vil mettes med $\mathrm{CO}_{2}$ hvis utslippene fortsetter. Når jeg likevel har valgt å se nærmere på denne "optimistmodellen," så er det på grunn av mulighetene som ligger i fangst og lagring av $\mathrm{CO}_{2}$ (Carbon Capture and Storage CCS). Det er velkjent at CCS kan redusere utslippene fra fossilt brensel, men i prinsippet kan metoden også fjerne karbon fra atmosfæren. Dette kan for eksempel gjøres ved at man fanger og lagrer $\mathrm{CO}_{2}$ fra forbrenning av fornybar biomasse. Hvor stor betydning slike tiltak kan ha i overskuelig framtid er imidlertid kontroversielt og svært usikkert.

Når $\mathrm{CO}_{2}$ absorberes i havet akkumuleres karbonet i forskjellige kjemiske forbindelser i de øvre lagene. Her har vi et kjemisk og biologisk kretsløp der karbon i organisk form og skall synker ned til havbunnen. I førindustriell tid var dette kretsløpet i balanse, men nå akkumuleres karbon i overflatelagene og fører til forsuring som er i ferd med å ødelegge livsgrunnlaget for skallformende organismer. Vegetasjonen på land øker i øyeblikket på grunn av gjødsling fra $\mathrm{CO}_{2}$, men dette vil også snart nå et metningspunkt fordi næringsstoffer og arealer er begrenset. Jeg har laget en enkel modell for metningen av $\mathrm{CO}_{2}$ absorbsjonen fra atmosfæren basert på resultater fra omfattende modeller for $\mathrm{CO}_{2}$-syklusen, og sammenholdt resultatet med optimistmodellen.

Man kan argumentere at det er inkonsekvent å bruke resultater fra komplekse modeller til å bestemme parameterne i den enkle modellen, men det finnes også observasjonsdata å bygge på. For 56 millioner år siden ble det av uklare grunner frigjort store mengder $\mathrm{CO}_{2}$ til atmosfæren i løpet av relativt kort tid (mindre enn 20 tusen år). Samtidig skjedde en temperaturøkning på nær seks grader. Denne hendelsen går under navnet Paleocen-Eocen Termisk Maksimum (PETM). Kunnskap om dette har man fra analyser av bunnsedimenter i havet, og disse viser at det tok omlag 170 tusen år før $\mathrm{CO}_{2}$ - konsentrasjonen var tilbake til sin normale likevekt. Denne likevekten er en balanse mellom $\mathrm{CO}_{2}$ som tilføres atmosfæren gjennom vulkansk aktivitet og $\mathrm{CO}_{2}$ som fjernes fra atmosfæren gjennom det hydrologiske kretsløpet. Dette skjer ved at $\mathrm{CO}_{2}$ i elver og innsjøer reagerer med mineraler i berggrunnen og produserer kalsiumkarbonat. Denne kjemiske forbindelsen føres med elvevannet ut i havet og deponeres til slutt som sedimenter på havbunnen som former kalkstein. Det er gode grunner til å tro at en stor del av de menneskeskapte utslippene vil ha en tilsvarende levetid i atmosfæren som utslippene under PETM (se Archer, 2010). 
Figur 2a illustrerer skjematisk utvekslingen av karbon mellom atmosfæren og havet, slik situasjonen er i dag. Havet tar opp mer karbon enn det avgir. Men med høyere atmosfærisk konsentrasjon og varmere hav, kan dette endres, slik at havet vil ikke være i stand til å ta opp mer karbon, og kanskje til og med begynne å avgi mer enn det tar opp.

\section{Strålingspådrivet}

Det er velkjent at økt konsentrasjon av drivhusgasser som $\mathrm{CO}_{2}$, metan, og nitrogenoksid forstyrrer jordas strålingsbalanse ved at en større del av varmestrålingen som sendes ut fra jordoverflaten blir absorbert og sendt tilbake til overflaten. Disse prosessene er godt forstått og det kan settes opp matematiske uttrykk som relaterer ubalansen mellom innstrålt og utstrålt energi til konsentrasjonen av disse drivhusgassene. Hver gass har forskjellig strålingspådriv, men vi behandler dem som om de var $\mathrm{CO}_{2}$ i den forstand at vi regner om konsentrasjonen til den tilsvarende konsentrasjonen av $\mathrm{CO}_{2}$ som gir det samme strålingspådrivet. Den samlede mengden av drivhusgasser $\mathrm{i}$ atmosfæren gis derfor i enheten $\mathrm{GtCO}_{2} \mathrm{e}$ (milliarder tonn $\mathrm{CO}_{2}$ ekvivalenter). Det er også verd å merke seg at i litteratur som omhandler karbonkretsløpet, der karbon inngår i forskjellige kjemiske forbindelser, så oppgir man gjerne atmosfærens $\mathrm{CO}_{2}$-innhold i gigatonn karbon (GtC). Siden et $\mathrm{CO}_{2}$ molekyl består av to oksygen-atomer i tillegg til karbon-atomet, så svarer $1 \mathrm{GtC}$ til $3.67 \mathrm{GtCO}_{2}$. Det er viktig å merke seg at strålingspådrivet ikke er proporsjonal med konsentrasjonen av drivhusgasser. Relasjonen er logaritmisk, slik at en eksponentiell økning av konsentrasjonen fører til en lineær økning av strålingspådrivet.

Noen tall er nyttige å ha med seg når man diskuterer karbonkretsløpet og global oppvarming. Konsentrasjonen av $\mathrm{CO}_{2}$ oppgis ofte i ppm (parts per million), altså antall $\mathrm{CO}_{2}$ molekyler i en mengde luft som inneholder en million molekyler. $\mathrm{CO}_{2-}$ konsentrasjonen i atmosfæren har økt fra 280 til 400 ppm siden førindustriell tid, og hele atmosfæren inneholder $760 \mathrm{GtC}$. Havet inneholder $38000 \mathrm{GtC}$, jordsmonn og vegetasjon på land $2300 \mathrm{GtC}$, og alt fossilt karbon er estimert til $3700 \mathrm{GtC}$. De kjente utnyttbare reservene (under dagens økonomiske betingelser) er ca. $830 \mathrm{GtC}$. Sammenligner vi dette med de $250 \mathrm{GtC}$ som vi kan forbrenne innenfor togradersmålet, så er konklusjonen at 70 prosent av disse reservene må bli liggende urørt.

\section{Temperaturresponsen}

Modellen for temperaturøkning inneholder en effekt som ofte blir oversett. Når strålingsbalansen blir forskjøvet av økt $\mathrm{CO}_{2}$-konsentrasjon, og jorda totalt mottar mer energi enn den avgir til verdensrommet som varmestråling, så vil ikke dette umiddelbart gi en sterk økning i overflatetemperatur. Dette er fordi energien transporteres ned i det kalde dyphavet. Sirkulasjonen i havet, og spesielt den såkalte termohaline sirkulasjonen, er viktig for denne varmetransporten. Når varmt overflatevann strømmer mot polene vil fordampning føre til at vannet blir saltere samtidig som det avkjøles. I Nord-Atlanteren fører dette til at vannet til slutt får så høy tetthet at det synker ned og følger de dype havstrømmene inntil det på nytt stiger opp til overflaten i det Indiske hav eller i Stillehavet. Først når 
dyphavet oppnår en temperatur som setter en stopper for denne varmetransporten vil vi se det endelige resultatet i overflatetemperaturen. Dette kan ta hundrevis av år.

Vi vet ikke helt hvor stor denne tregheten i temperaturresponsen er, men jeg har lagt inn to ytterligheter i modellen slik at vi kan få et bilde av usikkerheten $\mathrm{i}$ projeksjonene. Figur $2 \mathrm{~b}$ viser hvordan overflatelaget i havet kan ha like mye energi som strømmer inn i laget som ut, og dermed ha tilnærmet konstant temperatur, mens jorda som helhet mottar mer innstråling fra sola enn den taper til verdensrommet i form av varmestråling fra overflaten. Varmeinnholdet i klimasystemet vil derfor fortsette å øke lenge etter at konsentrasjonen av drivhusgassene har sluttet å vokse. Denne økningen i varmeinnholdet manifesterer seg som en jevn økning av temperaturen i dyphavet, og overflatetemperaturen vil stige i takt med denne. Vi får altså en forsinket respons i overflatetemperaturen på grunn av den store varmekapasiteten til verdenshavene (se Vallis, 2011).

Klimamodeller som bare simulerer en atmosfære som utveksler varme med overflatelaget i havet, og ikke modellerer den fulle sirkulasjonen i havet, vil ikke få med seg denne forsinkete temperaturresponsen. Forskjellen kan bli som vist i Figur 3a, som viser responsen på et utslippsscenario gitt ved en eksponentiell vekst av utslippene. Dette scenarioet er gitt ved den blå kurven i Figur $3 \mathrm{~b}$ fram til år 2100, men fortsetter eksponentielt etter dette fram til år 2200. Den svarte kurven i Figur 3a er temperaturen uten forsinkelse i responsen, altså under en antakelse om at ingen varme lagres i havet. Den røde og blå kurven er beregnet for forskjellige grader av forsinkelse, og representerer to ytterligheter som angir usikkerheten i vår kunnskap om energiopptaket i havet. Grunnen til at overflatetemperaturen vokser rasker ved mer forsinket respons er at en av parameterne i modellen (klimasensitiviteten) må tilpasses slik at den gir den obbserverte temperaturutviklingen i perioden 1880-2015. Med større forsinkelse trenges større klimasensitivitet, og det vil gi større framtidig temperaturøkning for samme strålingspådriv.

\section{Utslippsscenarier}

Klimapanelet har laget en rekke scenarier for utslipp av drivhusgasser basert på forskjellige antakelser om utviklingen av verdensøkonomien og energisystemene, og jordsystemmodellene blir foret med disse scenariene. Resultatene er en lang rekke prognoser som er blitt presentert for politiske beslutningstakere. Figur $3 \mathrm{~b}$ inneholder en rekke mer stiliserte scenarier for utslipp som er puttet inn i den enkle modellen. Den eksponentielt voksende blå kurven er en ekstrapolering av den veksten i utslippene vi har sett i de siste tiårene. Fram til om lag 2070 sammenfaller denne kurven ganske godt med klimapanelets "business as usual" scenario. Den tekniske betegnelsen på dette scenariet er Representative Concentration Pathway 8.5 (RCP8.5). Etter 2070 avtar veksten i utslippene gradvis fram mot 2100 i dette scenariet. Scenariene i Figur 3b følger den eksponentielle banen opp til henholdsvis 2030, 2070, og 2110. Ved disse datoene blir det gjennomført klimatiltak med henholdsvis en prosent og fem prosent årlige reduksjoner av utslippene. En prosent regnes for å være en helt realistisk reduksjonsrate i en kapitalistisk økonomi der det finns 
politisk vilje, men fem prosent regnes å være grensen for hva som kan tåles uten økonomisk sammenbrudd. Figuren viser altså til sammen seks forskjellige utslippsscenarier.

\section{Temperaturprognoser}

Figur 4 og 5 viser prognosene for $\mathrm{CO}_{2}$-konsentrasjon og global overflatetemperatur for scenariene vist i Figur $3 \mathrm{~b}$. Resultatet av analysene er overraskende nok at ved fortsatt eksponentiell vekst av utslippene så er det liten forskjell på optimistmodellen og den mer realistiske varianten. Dette er fordi $\mathrm{CO}_{2}$-konsentrasjonen er nesten den samme i de to modellene så lenge utslippene $ø$ øer eksponentielt. Det er først når utslippene avtar at optimistmodellen gir synkende $\mathrm{CO}_{2}$-nivåer, mens den mer realistiske modellen gir fortsatt økning, men med lavere vekstrate, fram mot år 2200.

I følge disse prognosene vil temperaturen øke mellom 1.5 og 2 grader for hver generasjon som går uten effektive reduksjoner. Forskjellene mellom de to modellene viser seg først og fremst i temperaturutviklingen etter at det er iverksatt reduksjoner på mellom en og fem prosent per år. Optimistmodellen gir da at temperaturen vil nå et maksimum etter noen tiår og deretter avta, mens de andre modellene gir en fortsatt økning fram mot år 2200 til tross for at utslippene reduseres til null.

Budskapet fra disse studiene er klart. Togradersmålet kan bare nås hvis reduksjoner på minst en prosent per år iverksettes i løpet av de kommende tiårene. Tidspunktet for iverksettelse av reduksjonene er viktigere enn størrelsen av dem. Det er en farlig illusjon å tro at vi ennå har nok av tid.

\section{Videre lesing}

Archer, D., The Global Carbon Cycle (Princeton Primers in Climate), Princeton University Press, 2010.

Knutti, R., Projections of climate change: Climate sensitivity, cumulative carbon, Climate Change 2013: The Physical Science Basis: Working Group I Contribution to the Fifth Assessment Report. https://www.ipcc.ch/pdf/unfccc/cop19/2_knutti13sbsta.pdf

Rypdal, K., Global warming projection derived from an observation-based minimal model, Earth. Syst. Dynam. Discuss., 6, 178-183, 2015. http://www.earth-syst-dynam-discuss.net/6/1789/2015/esdd-6-17892015.pdf

Stocker, T. F., The Closing Door of Climate Targets, Science, 339, 280-282, 2013. https://www.sciencemag.org/content/339/6117/280.short

Vallis, G. K., Climate and the Oceans, (Princeton Primers in Climate), Princeton University Press, 2011. 


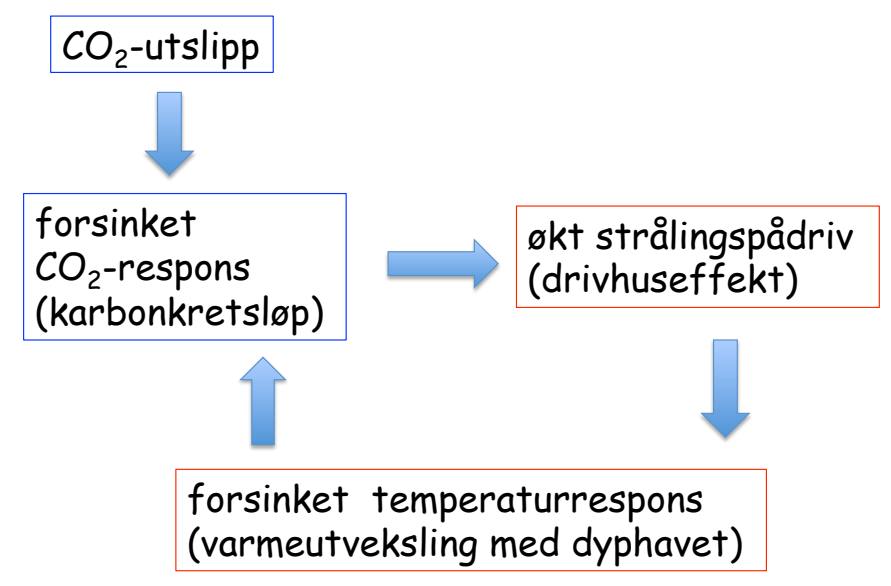

Figur 1: Et flytdiagram for forenklet klimamodell. $\mathrm{CO}_{2}$-utslipp inngår i karbonkretsløpet; havet og vegetasjonen tar etterhvert opp mindre $\mathrm{CO}_{2}$ og en større andel av utslippene akkumuleres i atmosfæren. Den økte $\mathrm{CO}_{2}-$ konsentrasjonen gir økt innstråling og overflaten svarer med en forsinket økning av temperaturen. Økningen av havets overflatetemperatur gjør havet mindre i stand til å holde på $\mathrm{CO}_{2}$.

(a) Forsinket $\mathrm{CO}_{2}$-respons

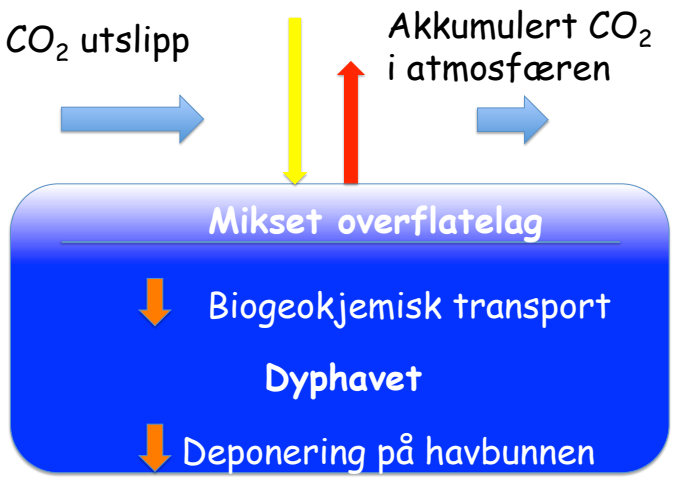

(b) Forsinket temperaturrespons

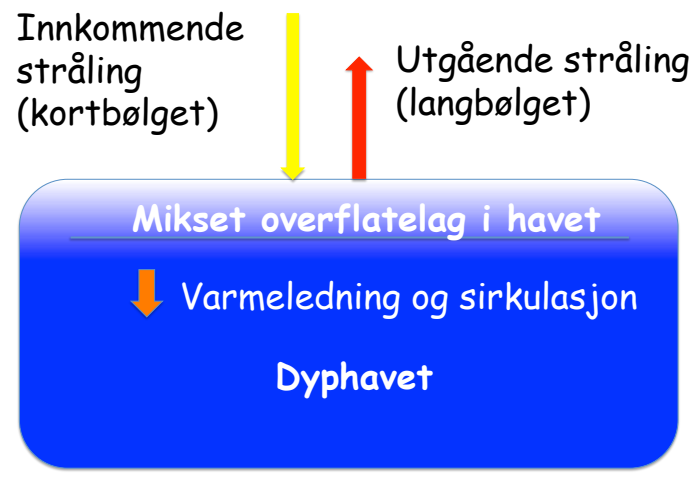

Figur 2: (a) Med økende utslipp av $\mathrm{CO}_{2}$ vil havet absorbere mer fra atmosfæren enn det avgir. $\mathrm{CO}_{2}$ oppløst i havvannet inngår i komplekse kjemiske og biologiske prosesser, og organisk bundet karbon blir langsomt transportert ned til havbunnen. Fordi transporten er langsom, akkumuleres stadig mer karbon i overflatelaget og fører til redusert opptak fra atmosfæren. (b) Varmetransport ned i dyphavet fører til at kloden mottar mer strålingsenergi enn den avgir uten at overflatetemperaturen øker vesentlig på kort sikt. 

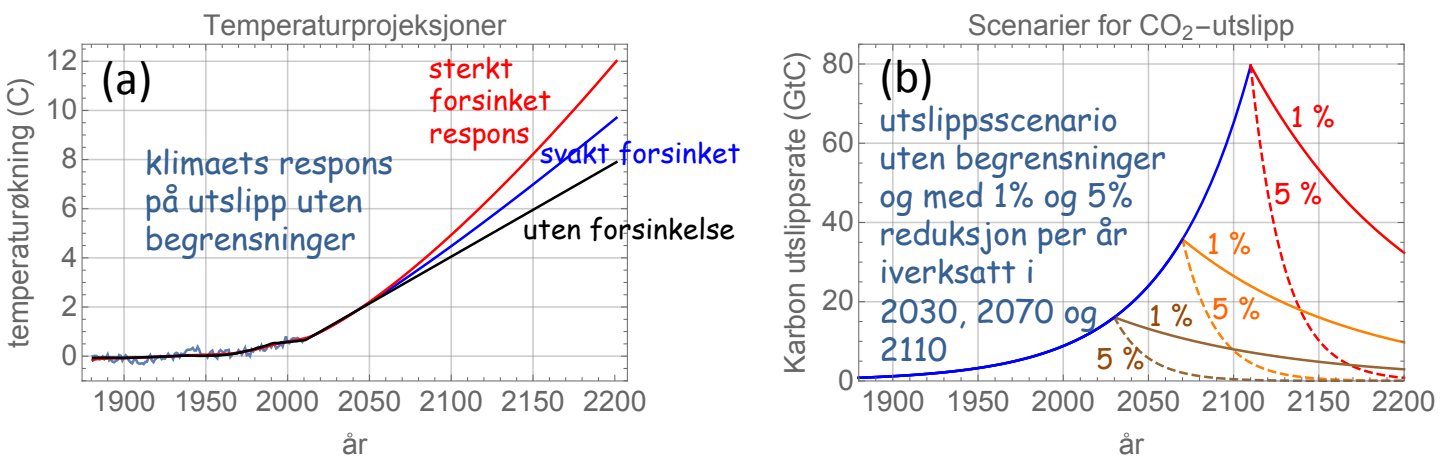

Figur 3: (a) Temperaturutvikling under et utslippscenario gitt ved den eksponentielt voksende blå kurven i (b) (som fortsetter å vokse eksponentielt etter år 2100). Svart kurve er utviklingen på en klode uten forsinkelser på grunn av akkumulasjon av varme i havet. Den sannsynlige temperaturutviklingen ligger et sted mellom den blå og den røde kurven. (b) Seks forskjellige scenarier for utslipp av $\mathrm{CO}_{2}$. De heltrukne brune, orange og røde kurvene viser utslipp som reduseres med 1 prosent per år. De stiplete kurvene med 5 prosent per år.
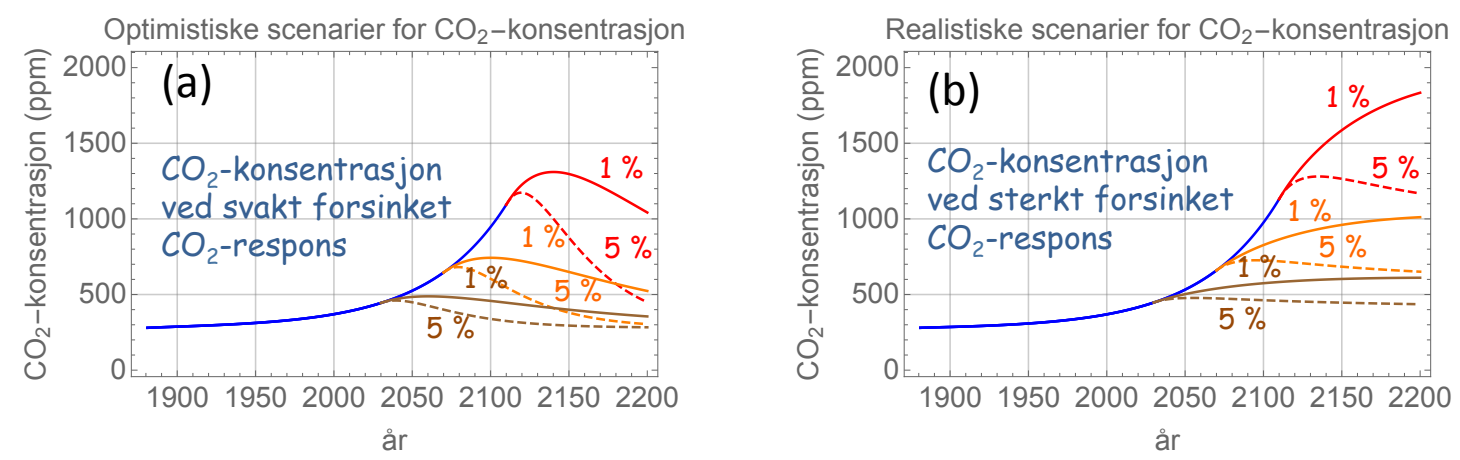

Figur 4: (a) Utvikling av atmosfærens $\mathrm{CO}_{2}$-konsentrasjon for de seks scenariene i Figur $3 \mathrm{~b}$ for optimistmodellen. I denne modellen absorberes halvparten av utslippene i hav og vegetasjon uavhengig av hvor høy $\mathrm{CO}_{2}$-konsentrasjonen blir. (b) Utviklingen i den mer realistiske modellen, der absorbsjonen av $\mathrm{CO}_{2}$ i hav og vegetasjon avtar når $\mathrm{CO}_{2}$-konsentrasjonen øker. 

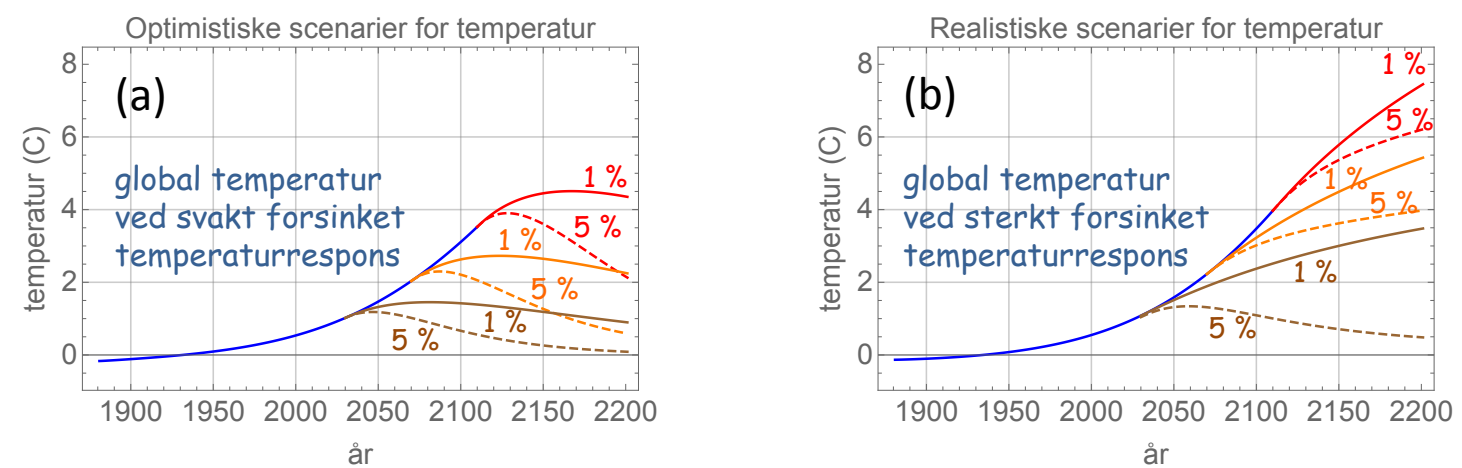

Figur 5. (a) Utviklingen av temperaturen i optimistmodellen. I denne modellen utvikler $\mathrm{CO}_{2}$-konsentrasjonen seg som i Figur $4 \mathrm{a}$ og forsinkelsen i temperaturresponsen antas å være liten, svarende til blå kurve i Figur 3a. (b) Utviklingen i den mer realistiske modellen, der $\mathrm{CO}_{2}$-konsentrasjonen utvikler seg som i Figur 4b og forsinkelsen i temperaturresponsen er stor; svarende til den røde kurven i Figur 3a. 